Subscriber access provided by lowa State University | Library

\title{
Article
}

\section{In-labeled glycoprotein non-metastatic b (GPNMB) targeted gemini surfactant-based nanoparticles against melanoma: In vitro characterization and in vivo evaluation in melanoma mouse xenograft model}

Amal Makhlouf, Istvan Hajdu, Siddesh v Hartimath, Elahe Alizadeh, Kayla Wharton, Kishor M. Wasan, Ildiko Badea, and Humphrey Fonge

Mol. Pharmaceutics, Just Accepted Manuscript • DOI: 10.1021/acs.molpharmaceut.8b00831 • Publication Date (Web): 03 Jan 2019

Downloaded from http://pubs.acs.org on January 4, 2019

\section{Just Accepted}

"Just Accepted" manuscripts have been peer-reviewed and accepted for publication. They are posted online prior to technical editing, formatting for publication and author proofing. The American Chemical Society provides "Just Accepted" as a service to the research community to expedite the dissemination of scientific material as soon as possible after acceptance. "Just Accepted" manuscripts appear in full in PDF format accompanied by an HTML abstract. "Just Accepted" manuscripts have been fully peer reviewed, but should not be considered the official version of record. They are citable by the Digital Object Identifier (DOI®). "Just Accepted" is an optional service offered to authors. Therefore, the "Just Accepted" Web site may not include all articles that will be published in the journal. After a manuscript is technically edited and formatted, it will be removed from the "Just Accepted" Web site and published as an ASAP article. Note that technical editing may introduce minor changes to the manuscript text and/or graphics which could affect content, and all legal disclaimers and ethical guidelines that apply to the journal pertain. ACS cannot be held responsible for errors or consequences arising from the use of information contained in these "Just Accepted" manuscripts. 

${ }^{111}$ In-labeled glycoprotein non-metastatic b (GPNMB) targeted gemini surfactant-based nanoparticles against melanoma: In vitro characterization and in vivo evaluation in melanoma mouse xenograft model

\begin{abstract}
Amal Makhlouf a,b, Istvan Hajdu ${ }^{\mathrm{a}}$, Siddesh V. Hartimath ${ }^{\mathrm{c}, \mathrm{d}}$, Elahe Alizadeh ${ }^{\mathrm{c}, \mathrm{d}}$, Kayla Wharton ${ }^{\mathrm{a}}$, Kishor M. Wasan ${ }^{\mathrm{a}}$, Ildiko Badea ${ }^{\mathrm{a}}$ and Humphrey Fongec,d,e*
\end{abstract}

\author{
aDrug Discovery and Development Research Group, College of Pharmacy and Nutrition, \\ University of Saskatchewan, 107 Wiggins Road, Saskatoon, SK, S7N 5E5, Canada \\ bepartment of Pharmaceutics and Industrial Pharmacy, Faculty of Pharmacy, Cairo University, \\ Kasr El-Aini, 12411, Cairo, Egypt

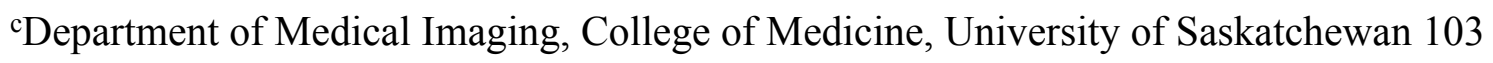 \\ University Drive, Saskatoon, SK, S7N 0W8, Canada \\ dSaskatchewan Centre for Cyclotron Sciences (SCCS), the Fedoruk Centre, Saskatoon SK, \\ Canada, 120 Maintenance Rd, Saskatoon, SK, S7N 5C4, Canada \\ eDepartment of Medical Imaging, Royal University Hospital Saskatoon, SK, 103 University \\ Drive S7N 0W8, Canada
}

\title{
Author for correspondence
}

*Humphrey Fonge, $\mathrm{PhD}$

103 Hospital Dr. 


\section{Department of Medical Imaging}

RUH Saskatoon, Saskatoon SK, S7N 0W8

\section{Canada}

Email: humphrey.fonge@usask.ca

Tel: 306-655-3353

Fax: 306-655-1637 


\section{Abstract}

Melanoma is a devastating form of skin cancer with high tendency to metastasis. This work addresses the development of new targeted nanoparticles that can be used for SPECT imaging of melanoma. Melanoma-specific glycoprotein non-metastatic b (GPNMB) antigen targeted and nontargeted gemini nanoparticles were prepared, characterized and radiolabeled with ${ }^{111}$ In. ${ }^{111}$ Inlabeled nanoparticles comprised of gemini surfactant grafted with monoclonal antibody Fab fragment that targets GPNMB. Specific uptake of GPNMB-Fab was studied in six melanoma cell lines using flow cytometry. In vitro cellular uptake and internalization was studied using flow cytometry, confocal laser scanning microscopy and radiometric techniques. Specific uptake of anti-GPNMB targeted nanoparticles was observed in GPNMB expressing cells which was higher than low expressing or control cells. In vitro studies showed that conjugation of GPNMB targeted nanoparticles led to enhanced intracellular uptake of the nanodelivery system which is critical for drug delivery. In vivo distribution of the nanoparticles was studied by microSPECT/CT imaging and ex vivo biodistribution. Tumor uptake was significantly higher $(p<0.05)$ in non-targeted nanoparticles $(5.47 \pm 0.46 \% \mathrm{IA} / \mathrm{cc})$ compared to GPNMB targeted nanoparticles $(1.87 \pm 0.27 \%$ ID/cc), which might be attributed to the high spleen uptake of the targeted formulation. These findings demonstrated that the radiolabeled gemini nanoparticles are promising for image-guided radiotherapy of melanoma. Formulation optimization is needed to improved tumor uptake and in vivo intracellular delivery for radiotherapeutic applications.

Key words: GPNMB Nanoparticles; Theranostics; ${ }^{111}$ Indium; Gemini; Melanoma; Imaging 


\section{Introduction}

Melanoma is the deadliest form of skin cancer due to its high propensity of metastasis and limited treatment options. The rise in the incidence of melanoma in the last 50 years is the highest among all cancers ${ }^{1}$. The five-year survival rates for melanoma that has metastasize to lymph nodes or other organs is $17 \%^{2}$. Early diagnosis and surgery are the patients' best hope for managing early stages of melanoma. The median progression-free survival for the FDA-approved pembrolizumab, while better than other therapies, is 5.5 months which is lower than the same treatment in lung cancer $(6.3 \text { months })^{3}$. Two approaches could reduce melanoma morbidity and mortality: early detection and the development of novel therapies to expand the current arsenal.

Novel nanoparticle formulations could address both areas: development of sensitive diagnostic tools and targeted delivery of curative agents. Enhanced permeability and retention effect (EPR) allows extravasation of the nanoparticles into the tumour through the leaky vasculature, leading to their preferential accumulation compared to healthy tissue ${ }^{4}$. In addition, nanoparticles might bypass certain uptake barriers such as epithelial tight junction ${ }^{5}$. Nanoparticles can be functionalized with targeting peptides and radionuclides for use as diagnostics and targeted radiotherapeutics ${ }^{6}$. Imaging and therapeutic radionuclides can be effectively delivered to tumor site by functionalized nanoparticles, thus improving imaging quality and therapeutic efficiency ${ }^{7}$. Our research group focuses on the design and synthesis of gemini surfactants to build drug delivery nanoparticles ${ }^{8,9}$. Gemini surfactants, N,N-bis(dimethylalkyl)- $\alpha, \omega$-alkanediammonium halide derivatives, have been shown to be attractive in the drug delivery field ${ }^{10}$. They are simply two surfactants chemically connected by a spacer. The physicochemical properties of these compounds can be modulated by the modification in the structure of the alkyl tails and the spacer groups. Alteration of the alkyl chain length, substitution of different functional groups and the degree of 
unsaturation provide the possibility to tailor specific compounds for a certain need ${ }^{9}$. Gemini surfactants self-assemble into nanoparticles, which adopt various morphologies (micelles, inverted micelles, liposomes, cubosomes) to deliver small and large molecules and radionuclides to tumor cells ${ }^{10}$.

Monoclonal antibody against glycoprotein NMB (GPNMB) was selected as a targeting vector. GPNMB is a 560-amino acid glycosylated transmembrane protein structurally similar to pMEL17, a melanocyte specific marker that is specifically expressed in melanoma cells ${ }^{11}$. Compared to healthy cells, tumours such as breast cancer, melanoma and glioblastoma overexpress GPNMB, presenting a new class of targets for these types of cancer ${ }^{12,13}$. Overexpression of GPNMB promotes metastasis, reduces cells apoptosis and increases angiogenesis in tumors ${ }^{14}$. Glembatumumab vedotin, an antibody drug conjugate of anti-GPNMB antibody and antimitotic agent monomethyl auristatin $\mathrm{E}$, is in clinical trials for melanoma and breast cancer ${ }^{15},{ }^{16},{ }^{17}$. However, the results have not been promising. A subgroup analysis (involving a small number of patients) of a phase II trial in triple negative breast cancer (TNBC) patients whose tumors overexpress GPNMB showed an advantage of glembatumumab vedotin over capecitabine $\left(\right.$ Xeloda $\left.^{\circledR}\right){ }^{16},{ }^{17}$. However, a recent pivotal phase IIb study in a large cohort of TNBC patients whose tumors overexpress $>25 \%$ of GPNMB, failed to show an advantage of glembatumumab vedotin over capecitatbine ${ }^{18}$. Unlike antibodies/ADCs against other antigens such as epidermal growth factor receptor II (HER 2) where the interaction of the antigen with other receptors has been shown to be responsible for poor response in some patients, the interaction of GPNMB with other receptors has not been well studied. Another factor responsible for poor efficacy of antibody drug conjugates is the presence of drug efflux pump multidrug resistance gene ${ }^{19}$. 
${ }^{111}$ In was selected as the imaging radionuclide as its physical decay $\left(\mathrm{t}_{1 / 2} 2.8\right.$ days $)$ is ideally suited for single-photon emission computed tomography (SPECT) imaging of long circulating nanodelivery systems. SPECT imaging has high sensitivity and good spatial resolution, and it is becoming an indispensable technique for in vivo imaging ${ }^{20}$. In this study we have used ${ }^{111}$ In to evaluate the in vivo properties of the nanodelivery system. The rationale for the choice of DOTA as chelating agent is that it can be used for imaging (with ${ }^{111} \mathrm{In}$ ) and subsequently for alpha particle therapy (actinium-225: ${ }^{225} \mathrm{Ac}$ ) for alpha particle radiotherapy. This allows us to use ${ }^{111}$ In as a surrogate to understand the in vitro and in vivo characteristics of the nanodelivery system. Alpha particle therapy causes irreversible DNA double-strand break due to its high linear energy transfer (LET), approximately $25-230 \mathrm{kEv} / \mu \mathrm{m}$, which is about 100 to 1000 times the average LET of beta particles ${ }^{21}$. The overall goal of the study was to develop and evaluate an ${ }^{111}$ In-labeled germini sulfactant nanodelivery system containing anti-GPNMB fab fragment in cells and mouse models of GPNMB overexpressing melanoma.

\section{Materials and methods}

\section{Materials}

Anti-GPNMB therapeutic antibody (glembatumumab) Fab (GPNMB-Fab) was purchased from Creative Biolabs NY, USA). Helper lipid 1, 2 dioleyl-sn-glycero-phosphatidylethanolamine (DOPE), 1,2 Dipalmitoyl-sn-glycero-phosphocholine (DPPC) and 1,2 Distearoyl-sn-glycerophosphocholine (DSPC) were purchased from Avanti Polar Lipids (Alabaster, AL).

${ }^{111}$ In was purchased from Nordion Inc. (Ottawa, ON). Activity measurements were made using a Biodex Atomlab 500 Dose Calibrator (Shirley, NY). For accurate quantification of activities, samples were counted for $1 \mathrm{~min}$ on a calibrated Perkin-Elmer Automatic Wizard2 
Gamma Counter (Waltham, MA). Labeling of nanoparticles with ${ }^{111}$ In was monitored using silicagel impregnated glass-fiber instant thin layer chromatography (iTLC) paper (Agilent Technologies, Santa Clara, CA).

\section{Formulation of gemini surfactant nanoparticles}

Lipid film hydration method was adopted to prepare gemini nanoparticles using DOPE, DPPC or DSPC as helper lipids. A homogenous lipid film was obtained by dissolving gemini surfactant, DOPE and DSPC or DPPC in anhydrous ethanol with the aid of sonication at room temperature for 10 minutes. Ethanol was then removed by evaporation under reduced pressure at $50^{\circ} \mathrm{C}$ using rotavap (BÜCHI Heating Bath B-490, vacuum pump V-700, Flawil). The lipid film was stored in $-80{ }^{\circ} \mathrm{C}$ for 12 hand freeze dried using Labconco ${ }^{\circledR}$ Freezone Plus $6 \mathrm{~L}$ cascade freeze dryer, MO, USA at $-80{ }^{\circ} \mathrm{C}$ and $0.03 \mathrm{mBar}$ pressure for $24 \mathrm{~h}$ to remove ethanol residues. Nanoparticles are formed by hydration of the lipid film using isotonic sucrose solution $(9.25 \%)$ in phosphate buffered saline of pH 7.4 (PBS) (HyClone $^{\mathrm{TM}}$, Hyclone Laboratories. Logan UT). Lipid film hydration was performed by ultrasonication (Elma ultrasonic, Singen) at $50{ }^{\circ} \mathrm{C}$ for two hours. The obtained nanoparticle suspension was filtered through Acrodisc $^{\circledR} 0.45 \mu \mathrm{m}$ syringe filter (Pall Gelman, Ann Arbor, MI). Table 1 summarizes the composition of the prepared gemini nanoparticles. In all analyses, triplicate batches of each formulation were evaluated.

\section{Characterization of gemini surfactant nanoparticles}

The size and zeta-potential of the particles were measured using Zetasizer Nano ZS instrument (Malvern Instrument, UK). Results are reported as the mean of $3-5$ measurements \pm standard deviation. Aliquots of $10 \mu \mathrm{L}$ samples were dropped onto 300-mesh formvar-coated copper grids 
(SPI Supplies). The water was blotted with absorbent tissue and samples were examined using Philips CM10 electron microscope (Eindhoven, The Netherlands).

\section{Preparation of fluorescent labeled gemini surfactant nanoparticles}

The lipophilic marker (DiO; ex/em wavelength $484 \mathrm{~nm} / 501 \mathrm{~nm}$ ) was integrated in the lipid film at a final concentration of $0.2 \mathrm{mg} / \mathrm{mL}$ of nanoparticle dispersion, while the hydrophilic tracer (FITC-Dextran; ex/em wavelength $492 \mathrm{~nm} / 518 \mathrm{~nm}$ ) was dissolved in the hydration solution at concentration of $1 \mathrm{mg} / \mathrm{mL}$. Nanoparticles were prepared applying the same procedures as mentioned before.

\section{Flow cytometry analysis}

After initial passage in tissue culture flasks, RPMI-7951 and A375cells were grown in 6-well plates. When reached $70-80 \%$ confluence, the cells were washed with PBS and treated with FBS free medium containing 10\% fluorescent gemini nanoparticle dispersion or dye solution in PBS $\left(0.2 \mathrm{mg} / \mathrm{mL}\right.$ for Dio and $1 \mathrm{mg} / \mathrm{mL}$ for FITC-dextran). After two hours incubation at $37^{\circ} \mathrm{C}$, cells were washed with PBS, collected by trypsinisation, pelleted, washed with $4 \mathrm{~mL}$ PBS and resuspended in $500 \mu \mathrm{L}$ PBS for flow cytometry.

Flow cytometric analysis (FACS analysis) for nanoparticles' fluorescence was performed using a 4-color FACS-Calibur (Becton Dickinson, Heidelberg, Germany) equipped with an argon laser exciting at a wavelength of $488 \mathrm{~nm}$. For each sample, 10000 events were collected by listmode data that consisted of side scatter, forward scatter and fluorescence emission centered at 530 nm (FL1) for DiO and FITC-dextran. For Alexa Flour ${ }^{\circledR}$ 647detection, a long-pass filter with a cutoff of 670 nm (FL3) was applied. Cell Quest Pro software (Becton Dickinson, Heidelberg, Germany) was applied for the analyses. 


\section{Confocal laser scanning microscopy}

For confocal microscopy, the cells were grown on cover slips in 6-well-plates, and the same procedures for cellular uptake experiment were followed but after incubation and washing, the cells were treated with FBS free medium and imaged using Leica TCS SP5 laser scanning confocal microscope (Leica microsysytems Inc., Benshein, Germany). LAS Af Lite 2.4.1 (Leica microsystems CMS GmbH) and FijiJ 1.44 (National Institute of Health, Bethesda MD) were used for image processing.

\section{Synthesis of lysine-, DOTA-, and GPNMB-Fab-conjugated gemini surfactants}

The synthesis of lysine-, DOTA-, and Fab-conjugated gemini surfactants are illustrated in Scheme 1. All reactions were carried out under a nitrogen atmosphere using standard Schlenk techniques. Mass spectra were obtained using a QSTAR XL MS/MS system. ${ }^{1} \mathrm{H}$ NMR spectra were recorded using a Bruker $500 \mathrm{MHz}$ Avance spectrometer. Chemical shifts, $\delta$, are reported in parts per million, referenced to the residual ${ }^{1} \mathrm{H}$ and ${ }^{13} \mathrm{C}\left(\mathrm{DMSO}-\mathrm{d}_{6}\right.$ at $\left.2.50,39.58\right)$, respectively. Purity of the compounds was further verified by reversed-phase (RP) HPLC (RP-HPLC) using an Agilent 1200 Series HPLC coupled to an UV detector and Waters 2796 HPLC System coupled to an UV and radiometric detector (Fig. S.1).

The synthesis of the N,N'-(((2-aminoacetyl)azanediyl)bis(propane-3,1-diyl))bis(N,Ndimethylhexadecan-1-aminium) chloride (16-7NG-16) gemini surfactants used in this study have been previously described ${ }^{22}$.

\section{Synthesis of lysine-conjugated gemini surfactants}

In step 1a, bis-boc-lysine, HATU, and DIPEA were sequentially placed in a 100-mL Schlenk flask containing $20 \mathrm{~mL}$ DMF at inert atmosphere to give a pale-yellow and later to a dark-red 
mixture. After stirring for 15 min, 16-7NG-16 was added. DMF was removed under high vacuum after stirring for $18 \mathrm{~h}$. To the residue, $100 \mathrm{~mL}$ DCM was added and then extracted with saturated sodium bicarbonate $(5 \times 100 \mathrm{~mL})$. The extracted organic layer was dried over anhydrous sodium sulfate, and concentrated under vacuum to give the reddish oily compound. In the next step (step 2b) the product was dissolved in $20 \mathrm{~mL}$ dry DCM followed by the addition of 10 mole equivalents of $\mathrm{HCl}$ (4 $\mathrm{M}$ in dioxane). After stirring for $2 \mathrm{~h}$, excess solvent was removed and the residue was washed by decantation with diethyl ether. Finally, DCM was added to dissolve the compound and then it was precipitated using diethyl ether. This was repeated three times before the sample was dried under high vacuum. The final product 16-7NGK-16 had a yellowish to orange color.

16-7NGK-16: ${ }^{1} \mathrm{H}$ NMR (500 MHz, DMSO-d $\left.{ }_{6}\right): \delta=8.93$ (m) 1H, 8.44 (m) 3H, 8.27 (m) 3H, 4.15 (d) $1 \mathrm{H}, 4.04(\mathrm{~d}) 1 \mathrm{H}, 3.90(\mathrm{~m}) 1 \mathrm{H}, 3.33(\mathrm{~m}) 12 \mathrm{H}, 3.04(\mathrm{~s}) 6 \mathrm{H}, 3.04$ (s) $6 \mathrm{H}, 2.72(\mathrm{~m}) 4 \mathrm{H}, 2.01(\mathrm{~m})$ 2H, $1.91(\mathrm{~m}) 2 \mathrm{H}, 1.77(\mathrm{~m}) 2 \mathrm{H}, 1.68-1.59(\mathrm{~m}) 6 \mathrm{H}, 1.45(\mathrm{~m}) 2 \mathrm{H}, 1.23(\mathrm{~m}) 50 \mathrm{H}, 0.84(\mathrm{t}) 6 \mathrm{H} . \mathrm{MS}-$ TOF (m/z); calculated for $\mathrm{C}_{50} \mathrm{H}_{106} \mathrm{~N}_{6} \mathrm{O}_{2}{ }^{2+}$; expected 411.4183, found 411.4094 .

\section{Synthesis of DOTA-conjugated gemini surfactants}

In step 2, $0.014 \mathrm{mmol}$ of $16-7 \mathrm{NG}-16$ was dissolved in $2 \mathrm{~mL}$ DMSO. After stirring for $15 \mathrm{~min}$, p-SCN-Bn-DOTA 0.014 mmol was added to the solution and the $\mathrm{pH}$ of the solution was adjusted to 8.5 by adding DIPEA. The mixture was stirred for 24 hours. The solvent was removed under vacuum and the product was separated by column chromatography (C18-reversed phase silica gel) eluting with water/acetonitrile. The appropriate fraction was freeze dried to obtain the N,N'-(((2(3-(4-((1,4,7,10-tetracarboxy-1,4,7,10-tetraazacyclododecan-2-

yl)methyl)phenyl)thioureido)acetyl)azanediyl)bis(propane-3,1-diyl))bis(N,N-

dimethylhexadecan-1-aminium) chloride, 16-7NG-DOTA-16, DOTA modified gemini surfactant solid product. The purity was further verified on RP-HPLC using Phenomenex Gemini-NX 
(Phenomenex, United States) C18 analytical column ( $3 \mu \mathrm{m}, 4.6 \mathrm{~mm}$ X $150 \mathrm{~mm})$. Gradient elution was performed at a flow rate of $1 \mathrm{~mL} / \mathrm{min}$ using an Agilent 1200 Series HPLC system. Detection was performed using an Agilent absorbance detector at $254 \mathrm{~nm}$. The mobile phase consisted of $0.1 \%$ trifluoroacetic acid in $\mathrm{H}_{2} \mathrm{O}$ (solution $\mathrm{A}$ ) and $0.1 \%$ trifluoroacetic acid in acetonitrile (solution B). The mobile phase was programmed as follows: gradient from $90 \% \mathrm{~A}: 10 \% \mathrm{~B}$ to $10 \% \mathrm{~A}: 90$ $\% \mathrm{~B}$ in $30 \mathrm{~min}$.

16-7NG-DOTA-16: ${ }^{1} \mathrm{H}$ NMR (500 MHz, DMSO-d $)$ ) $\delta=7.52(\mathrm{~m}) 2 \mathrm{H}, 7.26(\mathrm{~m}) 2 \mathrm{H}, 4.40$ (m) 2H, $3.43 \mathrm{~m} \mathrm{25H}, 3.24$ (m) 9H, 2.99 (s) 6H, 3.03 (s) 6H, 2.55 (s) 3H, 2.04 (brs) 2H, 1.90 (brs) 2H, 1.65 (brs) $4 \mathrm{H}, 1.24(\mathrm{~m}) 50 \mathrm{H}, 0.86(\mathrm{t}) 6 \mathrm{H}$. MS-TOF (m/z); calculated for $\mathrm{C}_{64} \mathrm{H}_{119} \mathrm{~N}_{9} \mathrm{O}_{9} \mathrm{~S}^{2+}$; expected 594.9420 , found 594.9405.

\section{Synthesis of GPNMB-Fab-conjugated gemini surfactants}

In step 3, $0.144 \mathrm{mmol}$ of 16-7NG-16 was dissolved in $10 \mathrm{~mL}$ DMSO. After stirring for $15 \mathrm{~min}$, $0.144 \mathrm{mmol}$ of NHS-PEG $1000-\mathrm{COOH}$ was added to the solution and the $\mathrm{pH}$ of the solution was adjusted to 8.5 by adding DIPEA. The mixture was stirred for 24 hours and the solvent was removed under high vacuum. In the final step (step 4) EDC $(0.033 \mu \mathrm{mol})$ and NHS $(0.036 \mu \mathrm{mol})$ were added to a solution of $(0.028 \mu \mathrm{mol}) \mathrm{PEG}_{1000}-\mathrm{COOH}$ conjugated gemini in $150 \mu \mathrm{L} \mathrm{DMF}$ and the reaction mixture was stirred at room temperature for $2 \mathrm{~h}$. The crude product was directly added to the $1 \mathrm{~mL}$ GPNMB-Fab solution $(465 \mu \mathrm{g} / \mathrm{mL})$ in PBS and the mixture was stirred at $4{ }^{\circ} \mathrm{C}$ for 30 min. The resulting protein solution was purified by centrifugal filtration (molecular weight cutoff, 10,000 Da) with PBS to obtain gemini-PEG 1000 -Fab (16-7NG-Fab-16).

Preparation of DOTA-gemini surfactant nanoparticles (DOTA-NP) and GPNMB-FabDOTA-gemini surfactant nanoparticles (Fab-DOTA-NP) 
DOTA-gemini nanoparticles (DOTA-NP) were prepared by replacing $5 \%$ of total gemini (16NGK-16), that is $1 \%$ of the total lipid content, in formula GNP1 with DOTA-conjugated gemini surfactant (16-NG-DOTA-16) during the preparation of the lipid film, and the same procedures for the preparation of gemini nanoparticles were followed. Fab-DOTA-NP were prepared by replacing $5 \%(\mathrm{w} / \mathrm{w})$ of gemini surfactant content in formula GNP1 $(1 \% \mathrm{w} / \mathrm{w}$ of total lipid composition) with DOTA-conjugated gemini surfactant (16-NG-DOTA-16) and 5\% w/w of gemini surfactant in the formulation ( $1 \% \mathrm{w} / \mathrm{w}$ of total lipid composition) by Fab-conjugated gemini surfactant (16-NG-Fab-16) (Table 1). To prepare Fab-DOTA-NP, Fab-PEG-gemini aqueous solution $(0.4 \mathrm{mg} / \mathrm{mL})$ was added dropwise with continuous stirring to $0.5 \mathrm{~mL}$ of nanoparticle dispersion. After an incubation time of 30 minutes at $37^{\circ} \mathrm{C}$, the formula was stored at $-80^{\circ} \mathrm{C}$. The particle size and zeta potential of targeted (Fab-DOTA-NP) and non-targeted (DOTANP) nanoparticles was determined as earlier described.

\section{Fab-binding study using flow cytometry}

GPNMB-Fab and Fab-DOTA-NP were labeled using Alexa Fluor ${ }^{\circledR} 647$ (ex/em 650/668 nm) microscale protein labeling kit (Invitrogen, Eugene, OR, USA) according to the manufacturer's protocol. Melanoma-derived cell lines A375, G-361 and WM-115 (primary melanoma) and SH-4, SK-MEL-24 and RPMI-7951 (metastatic melanoma) were washed with PBS, detached using TrypLE $^{\mathrm{TM}}$ (gibco, USA), pelleted and resuspended in PBS at a final concentration of $2 \times 10^{6}$ cells $/ \mathrm{mL}$. One hundred microliters of cell suspension was incubated with $4.65 \mu \mathrm{g}$ of labeled Fab, or the equivalent amount of labeled nanoparticles, for one hour at room temperature. After incubation, cells were washed with PBS, pelleted and resuspended in $500 \mu \mathrm{L}$ PBS for FACS. To evaluate the non-specific binding, a control sample was prepared by incubating the cells with the same concentration of unlabeled GPNMB-Fab for half an hour, before adding the labeled Fab. 


\section{Radiolabeling and characterization of gemini surfactant nanoparticles}

DOTA-NP and Fab-DOTA-NP were incubated with ${ }^{111} \mathrm{In}$-acetate $\left({ }^{111} \mathrm{InCl}_{3} / 0.5 \mathrm{M}\right.$ ammonium acetate) for 1 hour at $37^{\circ} \mathrm{C}$. The radiochemical purity (RCP) of ${ }^{111}$ In-labeled nanoparticles was determined by instant thin layer chromatography (iTLC). Plates were developed in $20 \mathrm{mM}$ sodium citrate (pH 5.5). ${ }^{111}$ In-labeled DOTA-NP and ${ }^{111}$ In-labeled Fab-DOTA-NP remained at the origin $(\mathrm{Rf}=0)$, while free ${ }^{111}$ In-acetate migrated with the solvent front $(\mathrm{Rf}=1)$. The distribution of radioactivity in developed iTLC plates was determined using a automated gamma counter (2480 Wizard $^{2}$, PerkinElmer, Waltham MA). For stability evaluation, ${ }^{111}$ In- DOTA-NP and ${ }^{111}$ In- FabDOTA-NP were added to $0.5 \mathrm{~mL}$ PBS or mouse serum in 1:10 volume ratio and were incubated at $37^{\circ} \mathrm{C}$ for 72 hours. At different time points, samples were taken from the stock solution and analyzed. Stability was evaluated using iTLC as described above.

\section{In vitro binding and internalization}

In vitro subcellular fractionation study was performed following the manufacturer's protocol (Nuclei EZ Prep Nuclei Isolation Kit; Sigma-Aldrich, Saint Louis, MO) with slight modification. RPMI-7951 cells were seeded in 6 -well cluster plate at $4 \times 10^{5}$ cells per well the day prior to the assay and the medium was changed one hour prior to the assay. ${ }^{111} \mathrm{In}$-labeled targeted (Fab-DOTANP. $5.5 \mu \mathrm{M}$ GPNMB-Fab) and non-targeted (DOTA-NP) nanoparticles were added to the cells $(15 \mu \mathrm{L}, 0.25 \mathrm{MBq})$ and incubated in $5 \% \mathrm{v} / \mathrm{v} \mathrm{CO}_{2}$ humidified atmosphere at $37^{\circ} \mathrm{C}$ for $1,2,6$ and $24 \mathrm{~h}$. After incubation, cells were put on ice to stop internalization, washed twice with ice-cold PBS, detached with $0.25 \% \mathrm{w} / \mathrm{v}$ trypsin and the radioactivity was measured using a gamma counter. Thereafter, the cells were washed with acetate buffer $(\mathrm{pH}=2.6)$ to strip nanoparticles bound to cell surface and were washed with PBS again and measured using a gamma counter. Finally, the cell suspension was vortexed and incubated in ice for $10 \mathrm{~min}$ in the presence of Nuclei EZ Lysis 
Buffer for the isolation of nuclei from cells. The cells were then centrifuged for 5 min at $4{ }^{\circ} \mathrm{C}$ where the supernatant collected contains the cytoplasmic fraction. The cells were then resuspended again in Nuclei EZ Lysis Buffer, and the above procedure was repeated to collect the remaining cytoplasmic fraction. The final pellet containing intact cell nuclei was counted using $\gamma$-counter to determine the amount of ${ }^{111} \mathrm{In}$.

\section{Pharmacokinetics of ${ }^{111}$ In- DOTA-NP and ${ }^{111}$ In- Fab-DOTA-NP}

Normal athymic CD-1 nude mice $(n=4)$ were injected intravenously via a tail vein with $4-5$ MBq ${ }^{111}$ In- DOTA-NP and ${ }^{111}$ In- Fab-DOTA-NP. Blood samples were collected from a saphenous vein at $5 \mathrm{~min}, 15 \mathrm{~min}, 30 \mathrm{~min}, 2,4,6,24,48$ and $72 \mathrm{~h}$ post injection into a capillary tube. The volume of the blood was determined by measuring the length of the blood sample in the capillary tube using a digital caliper and converted to $\mathrm{mL}$ knowing the internal dimeter of the capillary tube. Thereafter, the radioactivity in the capillary tube was measured in a $\gamma$-counter and expressed as percentage of the injected activity per $\mathrm{mL}(\% \mathrm{IA} / \mathrm{mL})$. Pharmacokinetic parameters were calculated by fitting the blood radioactivity versus time to a two-compartment model using Prism 5.0 software (GraphPad). The area under the percentage of the injected activity per $\mathrm{mL}$ versus time curves (AUC), clearance (CL), volume of distribution (Vss), and half-lives $\left(t_{1 / 2 \alpha}\right.$, and $\left.t_{1 / 2 \beta}\right)$ were calculated.

\section{SPECT/CT imaging and biodistribution in mice}

Athymic CD-1 nude mice bearing G361xenografts $(n=4)$ were injected via a tail vein with 15 - $17 \mathrm{MBq}$ of ${ }^{111} \mathrm{In}-\mathrm{Fab}-\mathrm{DOTA}-\mathrm{NP}$ or of ${ }^{111} \mathrm{In}-\mathrm{DOTA}-\mathrm{NP}$. At 2, 24 and 48 hours after injection, SPECT and CT images were acquired using MILabs Vector ${ }^{4}$ CT scanner (MILabs B.V., Utrecht). SPECT scans were acquired in a list-mode data format with a high-energy ultra-high resolution 
(XUHS-M) mouse/rat pinhole collimator. Corresponding CT scans were acquired with a tube setting of $50 \mathrm{kV}$ and $480 \mu \mathrm{A}$. Images were reconstructed using a pixel-based order-subset expectation maximization (POS-EM) algorithm that included resolution recovery and compensation for distance-dependent pinhole sensitivity and were registered on CT and quantified using PMOD 3.8 software (PMOD, Switzerland). Tracer uptake was expressed as percentage injected activity (\% IA) per volume (cc) of tissue volume (\% IA/cc). All quantification data was reported as mean \pm standard deviation within one animal study group.

For biodistribution study, the animals were euthanized under deep anesthesia after the last imaging point and tissue samples including small intestine, stomach, lung, heart, muscle, liver, spleen, kidneys and tumor were harvested. Samples of selected tissues were excised and weighed and the amounts of radioactivity in tissue samples were measured using $\gamma$-counter. The radioactivity in the organs was expressed as percent injected activity per gram $(\% \mathrm{IA} / \mathrm{g})$.

All animal experiments comply with the ARRIVE guidelines ${ }^{23}$ and were carried out in accordance the National Institutes of Health guide for the care and use of Laboratory animals National Research Council (US) Committee for the Update of the Guide for the

Care and Use of Laboratory Animals, Guide for the Care and Use of Laboratory Animals, Guide for the Care and Use of Laboratory Animals, $2011<$ https://doi.org/10.17226/12910>.. The study protocol was approved by Animal Research Ethics Board (AREB), University of Saskatchewan (protocol number 20150044).

\section{Statistical analyses}

All characterization experiments were performed in triplicates at the minimum and the results are expressed as mean values \pm standard deviation. Statistical analyses was evaluated by one- 
way analysis of variance (ANOVA) followed by the Bonferroni post hoc test using SPSS version 23.0 (SPSS, IBM Company, Chicago, USA). Significant differences were considered at $\mathrm{p}<0.05$ values.

\section{Results}

\section{Formulation and characterisation of gemini surfactant nanoparticles}

Gemini surfactants nanoparticles were prepared using gemini surfactant (16-NGK-16), DOPE, DPPC and DSPC as helper lipids in different molar ratios (Table S.1). The prepared nanoparticles had a particle size ranging from $70-180 \mathrm{~nm}$. The polydispersity index (PDI) of the nanoparticles was approximately 0.2 and the zeta potential ranged from $10-17 \mathrm{mV}$ (see supplementary data). Formula GNP1 with particle size of $85.42 \pm 0.68 \mathrm{~nm}(\mathrm{PDI} 0.18 \pm 0.01)$ and zeta potential of 17.07 $\pm 1.18 \mathrm{mV}$ was chosen for DOTA and GPNMB Fab conjugation. TEM images (Fig. 1) show round particles less than $100 \mathrm{~nm}$ in diameter with no aggregations. The particle size of non-targeted gemini surfactant nanoparticles (DOTA-NP) and targeted gemini surfactant nanoparticles (FabDOTA-NP) was found to be $105.1 \pm 2.98 \mathrm{~nm}(\mathrm{PDI} 0.19 \pm 0.0125)$ and $127.566 \pm 2.45$ (PDI 0.341 $\pm 0.0006)$, respectively. Based on the size of Fab-DOTA-NP and the mean molecular area of GPNMB-Fab-conjugated gemini surfactants $\left(a_{0}=7\right)^{22}$, the number of GPNMB-Fab per one nanoparticle was calculated to be approximately 50 .

\section{Flow cytometry of gemini surfactant nanoparticles}

The cellular uptake of gemini surfactant nanoparticles formula GNP1 was investigated in two melanoma cell lines, RPMI-7951 and A375 using flow cytometry. Two fluorescent dyes; the hydrophilic FITC-dextran and the hydrophobic DiO were used to label the nanoparticles. Flow cytometry showed that cells treated with dye solutions exhibited small or no shift in their 
fluorescence compared to a significant shift observed with the fluorescent nanoparticles (Fig. 2), which was confirmed by confocal microscopy imaging (Fig. 3).

The binding of GPNMB-Fab conjugated nanoparticles in melanoma cell lines A375, G-361, WM-115, SH-4, SK-MEL-24 and RPMI-7951 was studied by flow cytometry (Fig.4). As a control, non-labeled antibody was used to block the receptors to study the specificity of binding. In case of RPMI-7951 cells, there was a remarkable shift in cell fluorescence in case of GPNMB-Fab-treated cells compared pre-blocked cells. In case of SH-4, the GPNMB-Fab treated cells and the preblocked cells were almost superimposed. The fluorescence shift in case of G361, SK-MEL-24 and A374 was less than that of RPMI-7951 but greater than for SH-4 cells. In order to investigate the effect of GPNMB-Fab conjugation with gemini surfactant nanoparticles on the binding to melanoma cells surface GPNMB receptors, the surface binding of Fab-DOTA-NP to two melanoma cell lines, namely, RPMI-7951 and A375 was investigated. There was no difference in fluorescence intensity between the unconjugated Fab and Fab-conjugated nanoparticles, indicating similar extent of binding at that concentration (Fig. 4 1b \& 2b).

\section{${ }^{111}$ In-labeling and stability of DOTA-NP and Fab-DOTA-NP}

The radiochemical purity in case of ${ }^{111}$ In-labeled DOTA-NP was $97.6 \pm 1.7 \%$ and in case of ${ }^{111}$ Inlabeled Fab-DOTA-NP was $98.2 \pm 1.6 \%$, therefore, no further purification was needed. Stability of the ${ }^{111}$ In labeled nanoparticles was studied in PBS and mouse serum using ITLC. No transchelation was observed for ${ }^{111}$ In-DOTA-NP after 72 hours incubation in mouse serum and PBS, while ${ }^{111}$ In-Fab-DOTA-NP showed a noticeable transchelation in mouse serum (3\%) and PBS (5.3\%). ${ }^{111}$ In-DOTA-NP and ${ }^{111}$ In-Fab-DOTA-NP were considered stable with only a small further increase in tranchelation after one week incubation (Fig. S.2). 


\section{Intracellular distribution of ${ }^{111}$ In-DOTA-NP and ${ }^{111}$ In-Fab-DOTA-NP}

We compared the in vitro intracellular distribution of non-targeted ${ }^{111}$ In-DOTA-NP and GPNMB targeted ${ }^{111}$ In-Fab-DOTA-NP (Fig. 5). Cell binding and intracellular uptake of targeted ${ }^{111}$ In-Fab-DOTA-NP was significantly $(p<0.05)$ higher than for non-targeted ${ }^{111}$ In-DOTA-NP at all time points. After one hour incubation $10.09 \pm 1.40 \%$ of ${ }^{111} \mathrm{In}-\mathrm{Fab}-\mathrm{DOTA}-\mathrm{NP}$ was bound to RPMI cells versus $2.75 \pm 0.71 \%$ of ${ }^{111}$ In-DOTA-NP $(p<0.05)$. Cell binding of nanoparticles peaked at six hours after incubation with $14.40 \pm 2.33 \%$ for ${ }^{111}$ In-Fab-DOTA-NP compared to $4.42 \pm 0.11 \%$ for ${ }^{111}$ In-DOTA-NP. Nuclear localization of GPNM targeted ${ }^{111}$ In-Fab-DOTA-NP was more than 5 -fold higher than $(p<0.05)$ for non-targeted ${ }^{111}$ In-DOTA-NP $(9.30 \pm 2.11 \%$ versus $1.85 \pm 0.33 \%$ ).

\section{Pharmacokinetics of ${ }^{111}$ In- DOTA-NP and ${ }^{111}$ In- Fab-DOTA-NP}

The pharmacokinetics of targeted ${ }^{111}$ In-Fab-DOTA-NP and non-targeted ${ }^{111}$ In-DOTA-NP was studied in healthy athymic CD-1 mice. ${ }^{111}$ In-Fab-DOTA-NP and ${ }^{111}$ In-DOTA-NP followed a biphasic elimination. There was a significant difference $(p<0.05)$ in the pharmacokinetic parameters of ${ }^{111} \mathrm{In}-\mathrm{Fab}-\mathrm{DOTA}-\mathrm{NP}(\mathrm{AUC}=67.0 \pm 13.2 \% \mathrm{IA} / \mathrm{mL} \times \mathrm{h}, \mathrm{Vss}=60.2 \pm 19.6 \mathrm{~mL}, \mathrm{CL}=1.22 \pm 0.21$ $\mathrm{mL} / \mathrm{h}$ and distribution half-life $\left.\mathrm{t}_{1 / 2 \alpha}=0.6 \pm 0.5 \mathrm{~h}\right)$ compared with ${ }^{111} \mathrm{In}$-DOTA-NP $(\mathrm{AUC}=127.9 \pm$ $13.8 \% \mathrm{ID} / \mathrm{mL} \times \mathrm{h}, \mathrm{Vss}=21.8 \pm 1.5 \mathrm{~mL}$ and $\mathrm{CL}=0.8 \pm 0.1 \mathrm{~mL} / \mathrm{h})$. There was no significant difference $(p>0.05)$ in the elimination half-life $t_{1 / 2 \beta}$ of the GPNMB targeted ${ }^{111}$ In-Fab-DOTA-NP $(27.4 \pm 3.6 \mathrm{~h})$ compared with non-targeted ${ }^{111}$ In-DOTA-NP $(21.6 \pm 2.1 \mathrm{~h})$ (Fig. 6 and Table 2).

\section{SPECT/CT imaging and biodistribution study in melanoma xenograft-bearing mice}

Representative slices of microSPECT/CT images of a mouse bearing G361 melanoma xenograft injected with ${ }^{111}$ In-Fab-DOTA-NP or ${ }^{111}$ In-DOTA-NP at 2, 24 and 48 hours post 
injection are shown (Fig. 7A \& B). It is to be noted that RPMI-7951 cell line, which shows the greater binding affinity to GPNMB-Fab, was not used in the imaging studies because it did not develop subcutaneous xenograft in mice.

There was lower tumor uptake of the GPNMB targeted ${ }^{111} \mathrm{In}$-Fab-DOTA-NP compared with non-targeted ${ }^{111}$ In-DOTA-NP at all time points. The high activity uptake by the liver and spleen is another important observation for both targeted and non-targeted nanoparticles. Quantification of the decay-corrected images (Fig. 7C) confirmed significantly $(p<0.05)$ higher tumor uptake of non-targeted nanoparticles: $5.23 \pm 0.55,5.77 \pm 0.57$ and $5.47 \pm 0.46 \% \mathrm{IA} / \mathrm{cc}$ at 2,24 and 48 hours, compared with the targeted nanoparticles; $1.53 \pm .01,2.08 \pm 0.36$ and $1.87 \pm 0.27 \% \mathrm{IA} / \mathrm{cc}$ at the corresponding time points. Ex vivo biodistribution results were similar to the microSPECT imaging (Fig. 8). The highest activity accumulation was observed in the liver and spleen for both the targeted and non-targeted nanoparticles. For instance, spleen uptake of ${ }^{111}$ In-Fab-DOTA-NP was $84.45 \pm 26.20$ versus $30.72 \pm 2.88 \% \mathrm{IA} / \mathrm{g}$ for ${ }^{111} \mathrm{In}$-DOTA-NP. On the other hand liver uptake for the targeted nanoparticles $(10.09 \pm 4.84 \% \mathrm{IA} / \mathrm{g})$ was significantly lower than that of the nontargeted nanoparticles $(21.32 \pm 1.26 \% \mathrm{IA} / \mathrm{g})$. Significantly higher uptake $(p<0.05)$ was seen in the lung, heart, skin and brain for the non-targeted ${ }^{111}$ In-DOTA-NP compared with the GPNMB targeted ${ }^{111} \mathrm{In}-\mathrm{Fab}-\mathrm{DOTA}-\mathrm{NP}$. Ex vivo biodistribution also confirmed higher tumor $(p<0.05)$ uptake of non-targeted ${ }^{111} \mathrm{In}-\mathrm{DOTA}-\mathrm{NP}(4.31 \pm 0.40 \% \mathrm{IA} / \mathrm{g})$ compared with ${ }^{111}$ In-Fab-DOTA-NP $(1.37 \pm 0.18 \% \mathrm{IA} / \mathrm{g})$ at 48 hours post injection.

\section{Discussion}

Gemini surfactants assemble spontaneously into complex supramolecular structures (micelles, bilayers and vesicles) 1000 -fold more efficiently compared to their monovalent analogues ${ }^{25}$. The 
low critical micelle concentration (CMC) is beneficial to minimize the amount of gemini surfactant needed in the formulation process, which in turn ensures an optimal safety profile and reduces the cost of the delivery system ${ }^{26}$. Cancerous cells overexpress the negatively charged phosphatidylserine on the cell membrane compared to normal tissues. Previous research results have found that human melanoma cells express a higher level phosphatidylserine compared to other cancer types ${ }^{27}$. This adds additional advantage to gemini surfactants nanoparticles, with cationic head groups, as a delivery system for cancer cells and specifically melanoma.

In the present study lipid film hydration method was applied to prepare gemini surfactantbased nanoparticles by the aid of DOPE, DPPC or DSPC. The particle size of the nanoparticles fell in the range of 50-200 $\mathrm{nm}$, which is optimal for cellular uptake ${ }^{28}$. Polydispersity index of the prepared formulae was $\leq 0.2$ indicating narrow range of particle size distribution ${ }^{29}$ (Table S.1). To study the cellular uptake of the gemini surfactant nanoparticles, two fluorescent dyes were loaded to the nanoparticles; the hydrophilic FITC-dextran $(\log p=2)^{30}$ and the hydrophobic DiO $(\log \mathrm{p}=5)^{31}$, and the cellular uptake was examined using flow cytometry (Fig. 2). It is clear that FITC-dextran and $\mathrm{DiO}$ are not taken up by the cells unless they are incorporated with the nanoparticles. Similar results could be seen in confocal microscopic images (Fig. 3) of cells internalising fluorescent nanoparticles while those treated with dye solutions exhibited little or almost no fluorescence.

Active targeting of nanoparticles with monoclonal antibodies can enhance their uptake by cancer cells that over express the target antigen ${ }^{32}$. Fab fragment-modified nanoparticles exhibit longer systemic circulation than those modified with whole immunoglobulin $G$ since reticuloendothelial system uptakes nanoparticles via the Fc receptor-mediated mechanism ${ }^{33,34}$. GPNMB is a glycosylated transmembrane protein that is overexpressed in melanoma among other 
types of cancer ${ }^{35}$. Anti-GPNMB antibody Fab fragment (GPNMB-Fab) was chosen as a targeting moiety. To understand the binding affinity of GPNMB-Fab to melanoma, six melanoma cell lines were screened by flow cytometry (Fig. 4). The cell lines were selected to represent different types of melanoma tumors and variable degrees of GPNMB antigen expression as reported in the literature. Three primary melanoma cell lines; A375, G-361 and WM-115, and three metastatic melanoma cells SH-4, SK-MEL-24 and RPMI-7951have been investigated. RPMI-7951, G361 and SK-MEL-24 are reported to be highly expressing GPNMB antigen ${ }^{11}$, A375 weakly expresses the antigen ${ }^{36}$, whereas, WM-115 and SH4 had not been tested before. The results showed that the degree of cellular binding depends on the level of antigen expression. RPMI-7951 cells showed the highest binding affinity among the cell lines tested, SH4 exhibited the lowest binding capacity, and the rest of the cell lines showed intermediate affinity compared to these two cell lines.

To formulate gemini surfactant nanoparticles radiolabeled with ${ }^{111}$ In and actively targeted with GPNMB-Fab, DOTA-conjugated gemini surfactant (16-7NG-DOTA-16) and Fab-conjugated gemini surfactant (16-7NG-Fab-16) were synthesized and characterised by mass spectroscopy, $1 \mathrm{H}$ NMR and RP-HPLC (Fig. S.1). Flow cytometry was used to confirm that conjugation did not affect binding to cells. Subcellular fractionation experiment was carried out to investigate the intracellular fate of ${ }^{111} \mathrm{In}$-labeled targeted $\left({ }^{111} \mathrm{In}\right.$-Fab-DOTA-NP) and non-targeted ( ${ }^{111} \mathrm{In}$-DOTANP) nanoparticles (Fig. 5). Over 24 hours, the surface binding and nuclear uptake of the targeted nanoparticle was significantly higher than the non-targeted nanoparticles. This indicates that GPNMB-Fab targeted nanoparticles can be more effective than non-targeted nanoparticles at releasing cytotoxic payloads to the vicinity of the nucleus of melanoma cancer cells where they can cause enhanced DNA damage and hence cell death ${ }^{37}$. 
As observed in the pharmacokinetic parameters, the AUC of the Fab-targeted nanoparticles $(67.0 \pm 13.2 \% \mathrm{IA} \mathrm{hr} / \mathrm{mL})$ is about half that of the non-targeted nanoparticles $(127.9 \pm 13.8 \% \mathrm{IA}$ $\mathrm{hr} / \mathrm{mL}$ ) which indicates that less of the targeted formulation was circulation for efficient tumor uptake. Similarly, the volume of distribution of the targeted nanoparticles $(60.2 \pm 19.6 \mathrm{~mL})$ was almost three times greater than non-targeted nanoparticles $(21.8 \pm 1.5 \mathrm{~mL})$ which reflects the high spleen uptake of the targeted nanoparticles. SPECT/CT imaging showed that tumor uptake in case of non-targeted nanoparticles was greater than the targeted nanoparticles (Fig. 7C), with maximum uptake at 24 hours. By decay corrected quantification of images, a significant difference in the radioactivity was detected between the targeted and non-targeted nanoparticles, with the greatest uptake $(5.77 \pm 0.57 \% \mathrm{IA} / \mathrm{cc})$ at 24 hours for the non-targeted nanoparticles. The main mechanism of targeting nanoparticulate delivery systems is passive targeting derived by the EPR effect which is due to the leaky vasculature and the poor lymphatic drainage of tumors ${ }^{38}$. The physicochemical properties of the nanoparticles such as the particle size, surface charge in addition to the tumor microenvironment, all determine the extent of nanoparticles extravasation to the tumor ${ }^{39}$. In our study, the non-targeted and targeted nanoparticles have the optimal size for tumor uptake (105.1 2.0 and $127.6 \pm 2.5 \mathrm{~nm}$, respectively). Besides, the positive surface charge imparted by gemini surfactant is favorable for tumor cells binding and uptake, as shown by flow cytometry and cell fractionation studies. Similar tumor uptake $(<7 \% \mathrm{IA} / \mathrm{cc})$ was shown for ${ }^{111} \mathrm{In}-\mathrm{labeled}$ liposomes in ovarian cancer xenografts ${ }^{40}$.

It is difficult to predict the in vivo behavior of targeted nano-delivery systems. Some studies have shown that conjugation of a targeting group improves tumor uptake while others have shown that it does not improve tumor uptake ${ }^{4}{ }^{42}$. A number of studies have shown that the active targeting of nanoparticle to epidermal growth factor receptors such as Her1/EGFR, and Her2 using 
ligands such as the epidermal growth factor (EGF) peptide and anti-Her2 monoclonal antibody fragments (Fab or single chain Fv) did not result in increased tumor uptake ${ }^{43,44}$. In this regard, Kirpotin et al showed that active targeting of liposome with anti-Her2 monoclonal antibody fragment did not lead to an increase in tumor uptake when compared with the non-targeted formulation ${ }^{45}$. In another study, Fonge et al showed that tumor uptake of the non-targeted block copolymer micelles was significantly higher than that of EGF-targeted micelles in a breast cancer xenograft model ${ }^{46}$. They also found that decreasing the density of the targeting moiety from 5 mol\% to $1 \mathrm{~mol} \%$ resulted in improved tumor uptake. In the same context, a novel anti-EphA2 targeted docetaxel antibody directed nanotherapeutic was formulated with $15 \mathrm{scFv} /$ liposome compared to 50 GPNMB-Fab fragments per nanoparticles in our study ${ }^{4748}$. In addition, the rapid blood clearance and high spleen uptake of the GPNMB targeted nanoparticles can be accounted for its low tumor uptake. In our case the lower tumor uptake of GPNMB targeted nanoparticles can be improved by further optimization of the formulation.

\section{Conclusion}

${ }^{111}$ In-labeled gemini surfactant-based nanoparticles were successfully optimized with respect to the particle size and surface charge to be optimal for endocytic internalization by tumor cells with minimal loss of ${ }^{111} \mathrm{In}$ in mouse serum and PBS upon incubation for one week. In a melanoma xenograft model, promising results are shown with the non-targeted formulation compared with GPNMB-targeted ones. One approach to improve tumor uptake of GPNMB targeted NP is to optimize the density of anti-GPNM Fab on the surface of the nanoparticles, as well as other physiochemical characteristics of the nano-delivery system.

\section{Acknowledgment}


This work was funded by Sylvia Fedoruk Canadian Centre for Nuclear Innovation (J2014/002, Imaging gene delivery nanoparticles targeted to melanoma), and Saskatchewan Health Research Foundation grant no. 3350 (Development of theranostic agents for melanoma). We also thank Waleed Mohammed-Saeid for his help in formulation development.

\section{Disclosure}

The author reports no conflicts of interest in this work.

\section{Supporting information}

Supporting information is available for Table S.1, Fig. S.1, and Fig. S.2. Material for chemical synthesis of compounds, formulation and characterization of gemini nanoparticles and cell culture are also available in the supporting data.

\section{References}

(1) Canadian Cancer Statistics Advisory Committee. Canadian Cancer Statistics; A 2018 Special Report on Cancer Incidence by Stage. Toronto, Can. Cancer Soc. 2018.

(2) Wolchok, J. How Recent Advances in Immunotherapy Are Changing the Standard of Care for Patients with Metastatic Melanoma. Ann. Oncol. 2012, 23 (Suppl 8), viii15-21.

(3) Gandhi, L.; Vansteenkiste, J. F.; Shepherd, F. A. 50 - Immunotherapy and Lung Cancer. In IASLC Thoracic Oncology (Second Edition); Harvey I. Pass, D. B. and G. V. S., Ed.; Philadelphia, 2018; p 501.

(4) Chen, J.; Shao, R.; Zhang, X. D.; Chen, C. Applications of Nanotechnology for Melanoma Treatment, Diagnosis, and Theranostics. Int. J. Nanomedicine 2013, 8, 2677-2688.

(5) Loo, Y.; Grigsby, C. L.; Yamanaka, Y. J.; Chellappan, M. K.; Jiang, X.; Mao, H. Q.; 
Leong, K. W. Comparative Study of Nanoparticle-Mediated Transfection in Different GI Epithelium Co-Culture Models. J. Control. Release 2012, 30 (160), 48-56.

Li, J.; Wang, Y.; Liang, R.; An, X.; Wang, K.; Shen, G.; Tu, Y.; Zhu, J.; Tao, J. Recent Advances in Targeted Nanoparticles Drug Delivery to Melanoma. Nanomedicine Nanotechnology, Biol. Med. 2015, April, 769-794.

(7) Kenny, G. D.; Villegas-Llerena, C.; Tagalakis, A. D.; Campbell, F.; Welser, K.; Botta, M.; Tabor, A. B.; Hailes, H. C.; Lythgoe, M. F.; Hart, S. L. Multifunctional Receptor-Targeted Nanocomplexes for Magnetic Resonance Imaging and Transfection of Tumours.

Biomaterials 2012, 33 (29), 7241-7250.

(8) Singh, J.; Yang, P.; Michel, D.; Verrall, R. E.; Foldvari, M.; Badea, I. Amino AcidSubstituted Gemini Surfactant-Based Nanoparticles as Safe and Versatile Gene Delivery Agents. Curr. Drug Deliv. 2011, 8 (3), 299-306.

(9) Yang, P.; Singh, J.; Wettig, S.; Foldvari, M.; Verrall, R. E.; Badea, I. Enhanced Gene Expression in Epithelial Cells Transfected with Amino Acid-Substituted Gemini Nanoparticles. Eur. J. Pharm. Biopharm. 2010, 75, 11-20.

(10) Singh, J.; Michel, D.; Getson, H. M.; Chitanda, J. M.; Verrall, R. E.; Badea, I. Development of Amino Acid Substituted Gemini Surfactant-Based Mucoadhesive Gene Delivery Systems for Potential Use as Noninvasive Vaginal Genetic Vaccination. Nanomedicine 2015, 10 (3), 405-417.

(11) Tse, K. F.; Jeffers, M.; Pollack, V. A.; McCabe, D. A.; Shadish, M. L.; Khramtsov, N. V.; Hackett, C. S.; Shenoy, S. G.; Kuang, B.; Boldog, F. L.; et al. CR011, a Fully Human Monoclonal Antibody-Auristatin E Conjugate, for the Treatment of Melanoma. Clin. 
Cancer Res. 2006, 15 (12), 1373-1382.

(12) Rose, A. A. N.; Grosset, A.; Dong, Z.; Russo, C.; Macdonald, P. A.; Bertos, N. R.; St-

Pierre, Y.; Simantov, R.; Hallett, M.; Park, M.; et al. Glycoprotein Nonmetastatic B Is an Independent Prognostic Indicator of Recurrence and a Novel Therapeutic Target in Breast Cancer. Clin. Cancer Res. 2010, 16 (7), 2147-2156.

(13) Rose, A. A. N.; Biondini, M.; Curiel, R.; Siegel, P. M. Targeting GPNMB with Glembatumumab Vedotin: Current Developments and Future Opportunities for the Treatment of Cancer. Pharmacol. Ther. 2017, Nov (179), 127-141.

(14) Rose, A. A. N.; Annis, M. G.; Dong, Z.; Pepin, F.; Hallett, M.; Park, M.; Siegel, P. M. ADAM10 Releases a Soluble Form of the GPNMB/Osteoactivin Extracellular Domain with Angiogenic Properties. PLoS One 2010, 5 (8), e12093.

(15) Ott, P. A.; Hamid, O.; Pavlick, A. C.; Kluger, H.; Kim, K. B.; Boasberg, P. D.; Simantov, R.; Crowley, E.; Green, J. A.; Hawthorne, T.; et al. Phase I/II Study of the Antibody-Drug Conjugate Glembatumumab Vedotin in Patients With Advanced Melanoma. J. Clin. Oncol. 2014, 32 (32), 3659-3666.

(16) Yardley, D. A.; Weaver, R.; Melisko, M. E.; Saleh, M. N.; Arena, F. P.; Forero, A.; Cigler, T.; Stopeck, A.; Citrin, D.; Oliff, I.; et al. EMERGE: A Randomized Phase II Study of the Antibody-Drug Conjugate Glembatumumab Vedotin in Advanced Glycoprotein NMB-Expressing Breast Cancer. J. Clin. Oncol. 2015, 33 (14), 1609-1619.

Ott, P. A.; Pavlick, A. C.; Johnson, D. B.; Hart, L. L.; Infante, J. R.; Luke, J. J.; Lutzky, J.; Rothschild, N. E.; Spitler, L. E.; Cowey, C. L.; et al. A Phase II Study of Glembatumumab Vedotin (GV), an Antibody-Drug Conjugate (ADC) Targeting GpNMB, in Advanced 
Melanoma. J. Clin. Oncol. 2017, 35 (15_suppl), 109.

(18) Celldex Therapeutics. Celldex's METRIC Study in Metastatic Triple-Negative Breast Cancer Does Not Meet Primary Endpoint.

http://ir.celldex.com/releasedetail.cfm?ReleaseID=1063842 2018, last accessed on $4 / 23 / 2018$

(19) Liu, Y.; Fang, J.; Joo, K. Il; Wong, M. K.; Wang, P. Codelivery of Chemotherapeutics via Crosslinked Multilamellar Liposomal Vesicles to Overcome Multidrug Resistance in Tumor. PLoS One 2014, 10 (3), e110611.

(20) Chattopadhyay, N.; Fonge, H.; Cai, Z.; Scollard, D.; Lechtman, E.; Done, S. J.; Pignol, J. P.; Reilly, R. M. Role of Antibody-Mediated Tumor Targeting and Route of Administration in Nanoparticle Tumor Accumulation in Vivo. Mol. Pharm. 2012, 9 (8), $2168-2179$.

(21) Elgqvist, J.; Frost, S.; Pouget, J.-P.; Albertsson, P. The Potential and Hurdles of Targeted Alpha Therapy - Clinical Trials and Beyond. Front. Oncol. 2014, 3 (324), 1-9.

(22) Al-Dulaymi, M. A.; Chitanda, J. M.; Mohammed-Saeid, W.; Araghi, H. Y.; Verrall, R. E.; Grochulski, P.; Badea, I. Di-Peptide-Modified Gemini Surfactants as Gene Delivery Vectors: Exploring the Role of the Alkyl Tail in Their Physicochemical Behavior and Biological Activity. AAPS J. 2016, 18 (5), 1168-1181.

(23) Kilkenny, C.; Browne, W.; Cuthill, I. C.; Emerson, M.; Altman, D. G. Animal Research: Reporting in Vivo Experiments: The ARRIVE Guidelines. Br. J. Pharmacol. 2010, 160 (7), 1577-1579.

(24) Guide for the Care and Use of Laboratory Animals, National Research Council (US) 
Committee for the Update of the Guide for the Care and Use of Laboratory Animals., 8th ed.; National Academies Press (US): Washington (DC), 2011.

(25) Kirby, A. J.; Camilleri, P.; Engberts, J. B. F. N.; Feiters, M. C.; Nolte, R. J. M.; Söderman, O.; Bergsma, M.; Bell, P. C.; Fielden, M. L.; García Rodríguez, C. L.; et al. Gemini Surfactants: New Synthetic Vectors for Gene Transfection. Angew. Chemie Int. Ed. 2003, $42(13), 1448-1457$.

(26) Menger, F. M.; Littau, C. A. Gemini-Surfactants: Synthesis and Properties. J. Am. Chem. Soc. $1991,113(4), 1451-1452$.

(27) Riedl, S.; Rinner, B.; Asslaber, M.; Schaider, H.; Walzer, S.; Novak, A.; Lohner, K.; Zweytick, D. In Search of a Novel Target - Phosphatidylserine Exposed by Non-Apoptotic Tumor Cells and Metastases of Malignancies with Poor Treatment Efficacy. Biochim. Biophys. Acta - Biomembr. 2011, 1808 (11), 2638-2645.

(28) Davis, M. E.; Chen, Z.; Shin, D. M. Nanoparticle Therapeutics: An Emerging Treatment Modality for Cancer. Nat. Rev. Drug Discov. 2008, 7 (9), 771-782.

(29) Michel, D.; Chitanda, J. M.; Balogh, R.; Yang, P.; Singh, J.; Das, U.; El-Aneed, A.; Dimmock, J.; Verrall, R.; Badea, I. Design and Evaluation of Cyclodextrin-Based Delivery Systems to Incorporate Poorly Soluble Curcumin Analogs for the Treatment of Melanoma. Eur. J. Pharm. Biopharm. 2012, 81 (3), 548-556.

(30) Hoffmann, A.; Bredno, J.; Wendland, M.; Derugin, N.; Ohara, P.; Wintermark, M. High and Low Molecular Weight Fluorescein Isothiocyanate (FITC)-Dextrans to Assess BloodBrain Barrier Disruption: Technical Considerations. Transl. Stroke Res. 2011, 2 (1), 106111. 
(31) Tibor Cserháti. Liquid Chromatography of Natural Pigments and Synthetic Dyes, 1st ed.; Elsevier: Amsterdam, 2007.

(32) Carter, T.; Mulholland, P.; Chester, K. Antibody-Targeted Nanoparticles for Cancer Treatment. Immunotherapy 2016, 8 (8), 941-958.

(33) Maruyama, K.; Ishida, O.; Takizawa, T.; Moribe, K. Possibility of Active Targeting to Tumor Tissues with Liposomes. Adv. Drug Deliv. Rev. 1999, 40 (1), 89-102.

(34) Kang, D. Il; Lee, S.; Lee, J. T.; Sung, B. J.; Yoon, J. Y.; Kim, J. K.; Chung, J.; Lim, S. J. Preparation and in Vitro Evaluation of Anti-VCAM-1-Fab'-Conjugated Liposomes for the Targeted Delivery of the Poorly Water-Soluble Drug Celecoxib. J. Microencapsul. 2011, $28(3), 220-227$.

(35) Rose, A. A. N.; Annis, M. G.; Frederick, D. T.; Biondini, M.; Dong, Z.; Kwong, L.; Chin, L.; Keler, T.; Hawthorne, T.; Watson, I. R.; et al. MAPK Pathway Inhibitors Sensitize BRAF-Mutant Melanoma to an Antibody-Drug Conjugate Targeting GPNMB. Clin. Cancer Res. 2016, 22 (24), 6088-6098.

(36) Qian, X.; Mills, E.; Torgov, M.; LaRochelle, W. J.; Jeffers, M. Pharmacologically Enhanced Expression of GPNMB Increases the Sensitivity of Melanoma Cells to the CR011-VcMMAE Antibody-Drug Conjugate. Mol. Oncol. 2008, 2 (1), 81-93.

(37) Zustovich, F.; Barsanti, R. Targeted $\alpha$ Therapies for the Treatment of Bone Metastases. Int. J. Mol. Sci. 2017, 19 (74), 1-12.

(38) Shargh, V. H.; Hondermarck, H.; Liang, M. Antibody-Targeted Biodegradable Nanoparticles for Cancer Therapy. Nanomedicine 2016, 11 (1), 63-79.

(39) Shi, J.; Kantoff, P. W.; Wooster, R.; Farokhzad, O. C. Cancer Nanomedicine: Progress, 
Challenges and Opportunities. Nat. Rev. Cancer 2017, 17 (1), 20-37.

(40) Ito, K.; Hamamichi, S.; Asano, M.; Hori, Y.; Matsui, J.; Iwata, M.; Funahashi, Y.; Umeda, I. O.; Fujii, H. Radiolabeled Liposome Imaging Determines an Indication for Liposomal Anticancer Agent in Ovarian Cancer Mouse Xenograft Models. Cancer Sci. 2016, 107 (1), $60-67$.

(41) Colombo, I.; Overchuk, M.; Chen, J.; Reilly, R. M.; Zheng, G.; Lheureux, S. Molecular Imaging in Drug Development: Update and Challenges for Radiolabeled Antibodies and Nanotechnology. Methods 2017, 130, 23-35.

(42) Pirollo, K. F.; Chang, E. H. Does a Targeting Ligand Influence Nanoparticle Tumor Localization or Uptake? Trends Biotechnol. 2008, 26 (10), 552-558.

(43) Lee, H.; Fonge, H.; Hoang, B.; Reilly, R. M.; Allen, C. The Effects of Particle Size and Molecular Targeting on the Intratumoral and Subcellular Distribution of Polymeric Nanoparticles. Mol. Pharm. 2010, 7 (4), 195-208.

(44) Hoang, B.; Ekdawi, S. N.; Reilly, R. M.; Allen, C. Active Targeting of Block Copolymer Micelles with Trastuzumab Fab Fragments and Nuclear Localization Signal Leads to Increased Tumor Uptake and Nuclear Localization in HER2-Overexpressing Xenografts. Mol. Pharm. 2013, 10 (11), 4229-4241.

(45) Kirpotin, D. B.; Drummond, D. C.; Shao, Y.; Shalaby, M. R.; Hong, K.; Nielsen, U. B.; Marks, J. D.; Benz, C. C.; Park, J. W. Antibody Targeting of Long-Circulating Lipidic Nanoparticles Does Not Increase Tumor Localization but Does Increase Internalization in Animal Models. Cancer Res. 2006, 66 (13), 6732-6740.

(46) Fonge, H.; Huang, H.; Scollard, D.; Reilly, R. M.; Allen, C. Influence of Formulation 
Variables on the Biodistribution of Multifunctional Block Copolymer Micelles. J. Control. Release 2012, 157 (3), 366-374.

(47) Geddie, M. L.; Kohli, N.; Kirpotin, D. B.; Razlog, M.; Jiao, Y.; Kornaga, T.; Rennard, R.; Xu, L.; Schoerberl, B.; Marks, J. D.; et al. Improving the Developability of an AntiEphA2 Single-Chain Variable Fragment for Nanoparticle Targeting. MAbs 2017, 9 (1), $58-67$.

(48) Kirpotin, D. B.; Tipparaju, S.; Huang, Z. R.; Kamoun, W. S.; Pien, C.; Kornaga, T.; Oyama, S.; Olivier, K.; Marks, J. D.; Koshkaryev, A.; et al. Abstract 3912: MM-310, a Novel EphA2-Targeted Docetaxel Nanoliposome. Cancer Res. 2016, 76 (14 Supplement), 3912. 


\section{Figure legends}

Scheme 1. Synthesis of (1) 16-7NGK-16; (2) 16-7NG-DOTA-16 and (3)16-7NG-Fab-16. Step 1a: bis-boc-lysine, HATU, DIPEA, DMF, 18 h. Step 1b: $4 \mathrm{M} \mathrm{HCl}$, dichloromethane, 2 h. (2) pSCN-Bn-DOTA, DIPEA, DMSO, 24 h. Step 3a: NHS-PEG ${ }_{1000}-\mathrm{COOH}$, DIPEA, DMSO, 24 h. Step 3b: Fab, EDC, NHS, DMF, 3 h.

Fig. 1. Transmission electron microscope (TEM) images of gemini surfactant nanoparticles formula GNP1 before and after lyophilisation.

Fig. 2. Cellular uptake of gemini surfactant nanoparticles in (1) RPMI-7951 and (2) A375 melanoma cells using flow cytometry: a) gemini surfactant nanoparticles loaded with FITCdextran and b) gemini surfactant nanoparticles loaded with DiO compared with dye solutions.

Fig. 3. Confocal microscopy images of RPMI-7951 cells (40×) treated with DiO labeled nanoparticles (1), DiO solution (2), FITC-dextran nanoparticles (3) and FITC-dextran solution (4); bright field (a), green filter (b) and merge(c)

Fig. 4. Flow cytometry analysis of GPNMB positive and negative cell lines. 1a) binding of unconjugated anti-GPNMB Fab to GPNMB positive RPMI-795 cells, 1b) binding of anti-GPNMB Fab nanoparticles to RPMI-795 cells; 2a) binding of unconjugated anti-GPNMB Fab to GPNMB positive A375 cells, 2b) binding of anti-GPNMB Fab nanoparticles to GPNMB positive A375 
cells.. Binding of anti-GPNMB Fab to 3) WM115, 4) SK-MEL-24, 5) G361 and 6) SH4 (6) melanoma cell lines is shown. NP = nanoparticle

Fig. 5. In vitro subcellular distribution of non-targeted ${ }^{111} \mathrm{In}$-DOTA-NP and targeted ${ }^{111} \mathrm{In}-\mathrm{Fab}-$ DOTA-NP in RPMI-7951 melanoma cells. Cancer cells were incubated for 1, 2, 6 and 24 h prior to subcellular fractionation. Gamma counting was performed for quantification of ${ }^{111}$ In-labeled nanoparticles in each subcellular fraction $(\mathrm{n}=3)$

Fig. 6. Pharmacokinetic profile of ${ }^{111} \mathrm{In}-\mathrm{Fab}-\mathrm{DOTA}-\mathrm{NP}$ and ${ }^{111} \mathrm{In}-\mathrm{DOTA}-\mathrm{NP}$ in athymic CD-1 nude mice bearing G361 xenografts (Error bars present standard deviation, $n=4$ ).

Fig. 7. Representative microSPECT/CT images of ${ }^{111} \mathrm{In}-\mathrm{Fab}-\mathrm{DOTA}-\mathrm{NP}(\mathrm{A})$ and ${ }^{111} \mathrm{In}-\mathrm{DOTA}-\mathrm{NP}$ (B) in mice bearing G361 melanoma xenograft at 2, 24 and 48 hours post injection. Red cycles indicate tumor, C) Tumor accumulation of ${ }^{111} \mathrm{In}-\mathrm{Fab}-\mathrm{DOTA}-\mathrm{NP}$ and ${ }^{111} \mathrm{In}-\mathrm{DOTA}-\mathrm{NP}$ by microSPECT/CT decay corrected image analysis. (Error bars present standard deviation, $\mathrm{n}=4$, * $\mathrm{p}<0.05)$

Fig. 8. Biodistribution of ${ }^{111}$ In-Fab-DOTA-NP and ${ }^{111}$ In-DOTA-NP in athymic CD-1 nude mice bearing G361 xenograft at 48 hours after intravenous injection (Error bars present standard deviation, $\mathrm{n}=4, * \mathrm{p}<0.05)$ 
Table 1. Composition (presented as \% w/w of total lipid) of the DOTA-gemini surfactant nanoparticles (DOTA-NP) and GPNMB-Fab-DOTA-gemini surfactant nanoparticles (Fab-DOTA-NP).

\begin{tabular}{ccccc}
\hline & $\begin{array}{c}\text { Fab-conjugated } \\
\text { gemini surfactant } \\
(16-N G-F a b-16)\end{array}$ & $\begin{array}{c}\text { DOTA-conjugated } \\
\text { gemini surfactant } \\
(16-N G-D O T A- \\
16)\end{array}$ & $\begin{array}{c}\text { Gemini } \\
\text { surfactant } \\
(16-7 N G-16)\end{array}$ & $\begin{array}{c}1,2 \text { dioleyl-sn-glycero- } \\
\text { phosphatidylethanolamine } \\
\text { (DOPE) }\end{array}$ \\
\hline $\begin{array}{c}\text { DOTA-gemini } \\
\text { surfactant } \\
\text { nanoparticles } \\
\text { (DOTA-NP) }\end{array}$ & - & $1 \%$ & $19 \%$ & $80 \%$ \\
$\begin{array}{c}\text { Fab-conjugated } \\
\text { gemini surfactant } \\
(16-N G-F a b-16)\end{array}$ & $1 \%$ & $1 \%$ & $18 \%$ & $80 \%$ \\
\hline
\end{tabular}


Table 2. Pharmacokinetic parameters of ${ }^{111} \mathrm{In}-\mathrm{DOTA}-\mathrm{NP}$ and ${ }^{111} \mathrm{In}-\mathrm{Fab}-\mathrm{DOTA}-\mathrm{NP}$.

\begin{tabular}{|c|c|c|c|c|c|}
\hline Formulation & $\begin{array}{c}\mathrm{AUC}^{\dagger} \\
(\% \mathrm{IA} \mathrm{hr} / \mathrm{mL})\end{array}$ & $\mathrm{V}_{\mathrm{ss}}^{\dagger}(\mathrm{mL})$ & $\mathrm{Cl}^{\dagger}(\mathrm{mL} / \mathrm{h})$ & $\mathrm{t}_{1 / 2 \alpha^{\dagger}}(\mathrm{h})$ & $\mathrm{t}_{1 / 2 \beta}(\mathrm{h})$ \\
\hline${ }^{111} \mathrm{In}-\mathrm{Fab}-\mathrm{DOTA}-\mathrm{NP}$ & $67.0 \pm 13.2$ & $60.2 \pm 19.6$ & $1.5 \pm 0.3$ & $0.6 \pm 0.5$ & $27.4 \pm 3.6$ \\
\hline${ }^{111}$ In-DOTA-NP & $127.9 \pm 13.8$ & $21.8 \pm 1.5$ & $0.8 \pm 0.1$ & $1.3 \pm 0.4$ & $21.6 \pm 2.1$ \\
\hline
\end{tabular}

$\dagger$ The difference between ${ }^{111}$ In-Fab-DOTA-NP and ${ }^{111}$ In-DOTA-NP was significant $(p<0.05)$ 


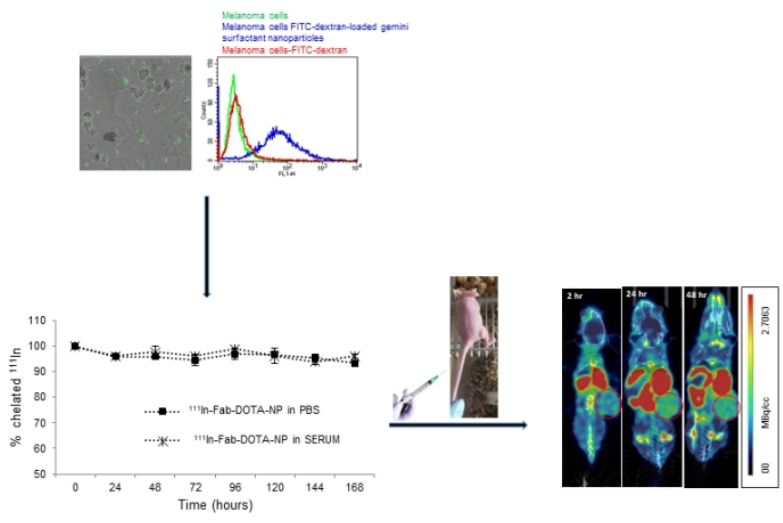

Graphical abstract $338 \times 190 \mathrm{~mm}(96 \times 96$ DPI) 


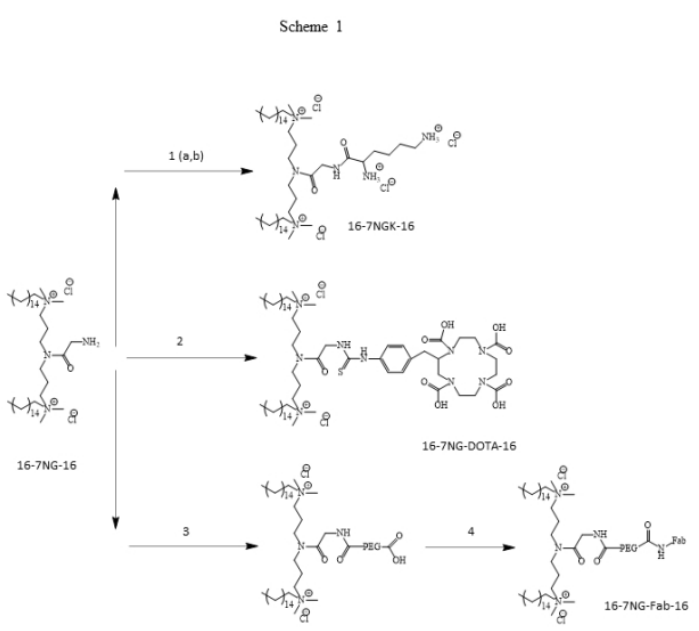

Scheme 1

$338 \times 190 \mathrm{~mm}(96 \times 96$ DPI) 


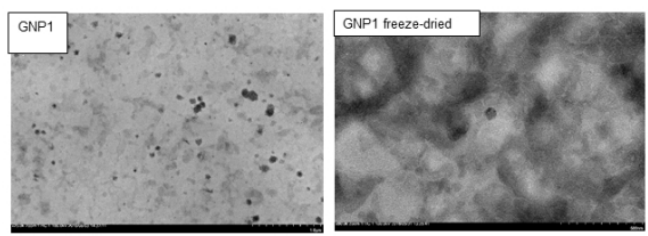

Fig. 1

338x190mm (96 x 96 DPI) 


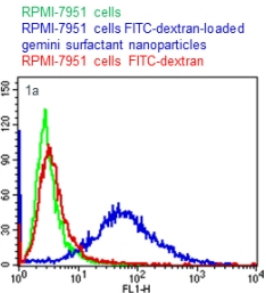

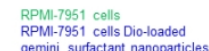
gemini sufactant nano
RPM-1.7951 calls Dio
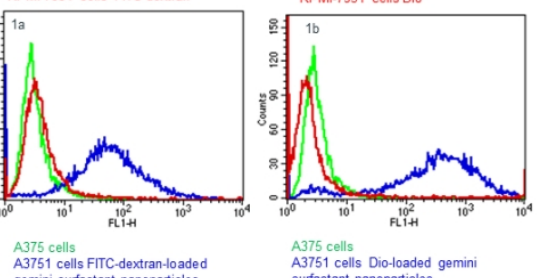

geminin surfactant nanopaticles
A375 cells FrTC-dextran

surfactant nanoparticles
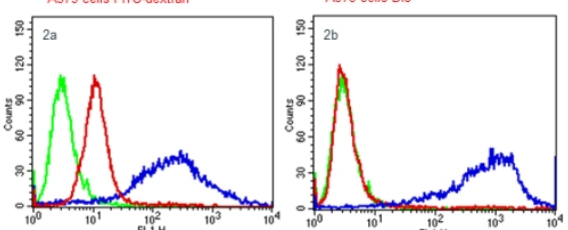

Fig. 2

338x190mm (96 x 96 DPI) 


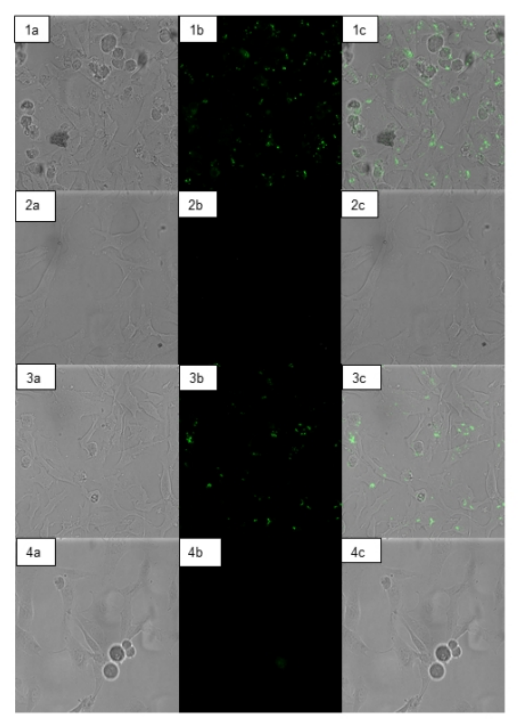

Fig. 3

$338 \times 190 \mathrm{~mm}(96 \times 96$ DPI) 

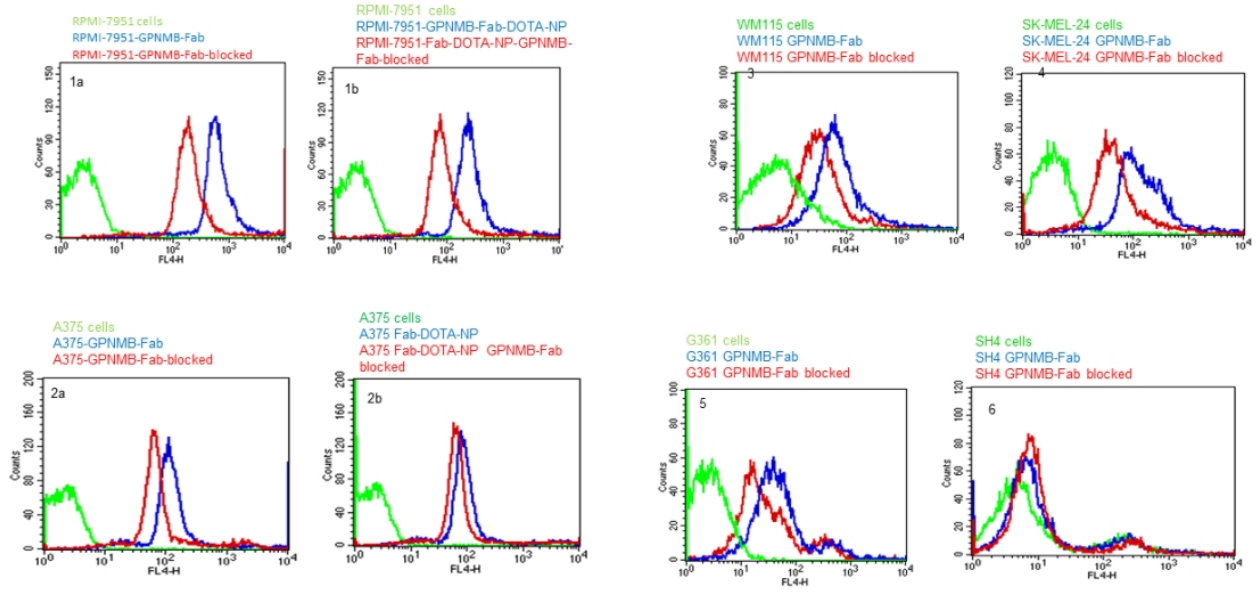

Fig. 4

338x190mm (96 x 96 DPI) 


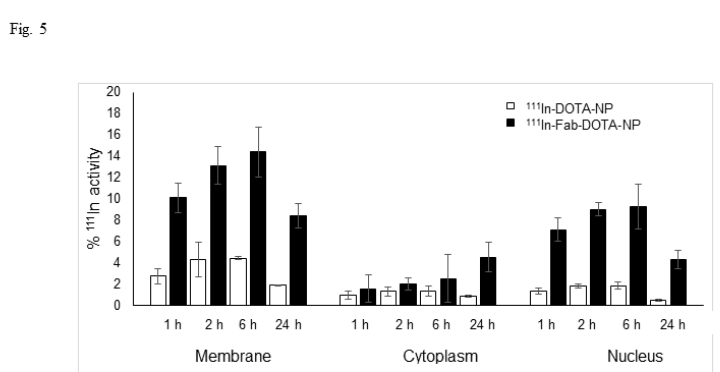

Fig. 5

$338 \times 190 \mathrm{~mm}(96 \times 96$ DPI) 


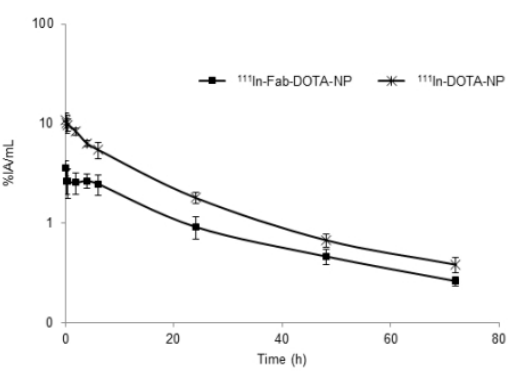

Fig. 6

$338 \times 190 \mathrm{~mm}(96 \times 96$ DPI) 


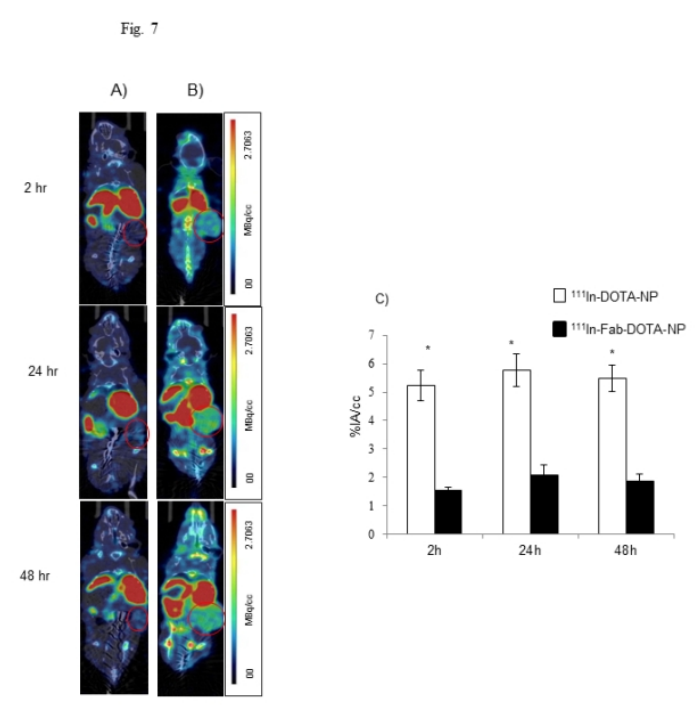

Fig. 7

$338 \times 190 \mathrm{~mm}(96 \times 96$ DPI) 
Fig. 8

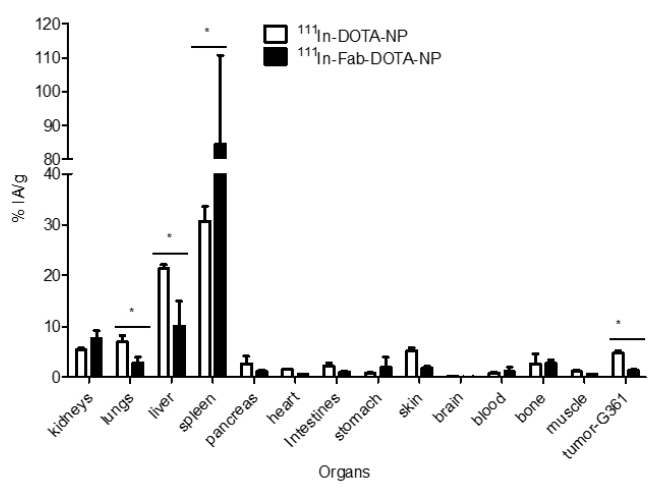

Fig. 8

$338 \times 190 \mathrm{~mm}(96 \times 96$ DPI) 